\title{
Principales planteamientos epistemológicos en el debate Lee, Macintosh, Mattessich
}

\author{
Main epistemological views in the debate: Lee-Macintosh-Mattessich \\ Carlos Emilio García Duque* \\ Docente Universidad de Caldas, Universidad de Manizales carlos.garcia_d@ucaldas.edu.co
}

Recibido el 6 De JULIO de 2020, APROBADO el 10 DE SEPTIEMBRE De 2020

\begin{abstract}
RESUMEN
En este artículo se examinan los principales planteamientos epistemológicos de un debate iniciado por Thomas Lee (2006) en el cual formuló algunas críticas a la propuesta que hizo el FASB en 2002, para formular estándares contables basados en principios (ECBP) e hizo algunos planteamientos sobre ciertos problemas estrictamente epistemológicos. En particular, Lee se ocupó del realismo, la naturaleza de los hechos contables, la noción de "fidelidad representacional" y los enfoques epistemológicos que considera más propicios para iluminar las actividades teórico-prácticas de la contabilidad. Para el análisis se tuvieron en cuenta las contribuciones, argumentos y contra-argumentos de Lee, Macintosh y Mattessich. Tras una presentación de sus principales planteamientos, se hace un balance de la discusión y se analizan los méritos de los argumentos de cada autor. Se concluye mostrando que, desde una perspectiva epistemológica, las tesis de Mattessich están mejor informadas y se apoyan en argumentos más fuertes y mejor articulados sobre aspectos como la naturaleza de la relación entre la teoría contable y los hechos de los que se ocupa, la función que cumple la información contable, sus principales características, la noción de "fidelidad representacional" y el carácter referencial de los conceptos contables.
\end{abstract}

\section{Palabras Clave}

Lee, Macintosh, Mattessich, información contable, representación, fidelidad representacional, realismo.

\section{Abstract}

In this paper I examine the main epistemological ideas in a debate initiated by Thomas Lee (2006) in which he advanced some criticisms against the 2002 FASB's proposal to formulate principle based accounting standards (PBAS) and made some remarks on certain problems strictly epistemological. In particular, Lee discussed realism, the nature of accounting facts, the notion of "representational faithfulness" and the epistemological views that he considered more promising to illuminate the theoreticalpractical activities of accounting. For this analysis I take into account the contributions, arguments and counter-arguments by Lee, Macintosh and Mattessich. After presenting their main views, I evaluate the discussion and analyze the merits of each perspective. I conclude by showing that, from an epistemological viewpoint, Mattessich's statements are better informed and rest upon stronger and better articulated arguments on aspects as the nature of the relationship between accounting theory and the facts treated by it, the role of accounting information, the notion of "representational faithfulness" and the referential character of the accounting concepts.

\section{KeYwORDS}

Lee, Macintosh, Mattessich, Accounting Information, Representation, Representational Faithfulness, Realism.

* (1) orcid.org/0000-0002-9248-8095 Google Scholar 


\section{Los planteamientos de Lee}

En 2002 el financial accounting standards board (FASB) propuso la adopción de estándares contables basados en principios (ECBP) para mejorar la práctica contable y fortalecer la profesión. El FASB buscaba mejorar la contabilidad financiera y asegurar que se usara su propio marco conceptual (MC), concebido desde 1976, en la formulación de nuevos estándares que incorporaran sus requisitos de reporte, medición y reconocimiento. Según el Consejo, comparados con los viejos estándares, los ECBP serían más amplios, contarían con menos excepciones, y requerirían más la opinión profesional (Lee, The FASB 1). Pero como lo documenta Lee, el $\mathrm{MC}$ no ha tenido mucho éxito en la tarea de mejorar los informes financieros corporativos; en lugar de fortalecer su naturaleza prescriptiva, se ha limitado a describir la práctica contable de donde proviene; en vez de articular los conceptos a los cuales se deben adaptar los datos contables, si queremos que sean útiles para determinar la riqueza y progreso de las entidades, se ha extraviado en la búsqueda de una explicación de las ideas que fundamentan la práctica convencional; como si esto fuera poco, el FASB no ha conseguido formular estándares consistentes con cualidades deseables como utilidad para la toma de decisiones, relevancia y confiabilidad; y los organismos que establecen los estándares contables se han aprovechado de la simple sugerencia de que se van a promover o buscar estas cualidades para legitimar su labor.

Para Lee, los continuos (y fallidos) esfuerzos del FASB por mejorar los informes financieros permiten inferir un compromiso con el realismo, pues adopta acríticamente la tesis de que dichos informes deben representar, de manera fidedigna, la realidad económica. En opinión de Lee, el principal problema de este proyecto radica en que el FASB no toma en consideración "los problemas de la realidad construida socialmente y su representación numérica" de acuerdo con las teorías de Searle (The FASB 2); por lo que sus recomendaciones de emplear estándares que puedan generar cifras que correspondan a la substancia económica de los eventos y transacciones comerciales relevantes; sus sugerencias sobre la existencia de una realidad económica (independiente de la contabilidad) y de que los informes financieros deben capturar objetivamente dicha realidad, no tienen más respaldo que el sentido común. Lee observa, correctamente, que proyectos como el de contabilidad para la realidad económica, y suposiciones como la confiabilidad de las representaciones (o de las medidas), 
entrañan importantes problemas filosóficos, y argumenta que si el FASB "continua ignorando o pasando por alto el significado filosófico de la realidad social y la correspondencia verdadera con respecto a la representación contable, los ECBP no podrán mejorar las prácticas de construcción de informes financieros corporativos" (The FASB 3).

En el marco de su caracterización de los esfuerzos del FASB por promover su MC para la construcción de ECBP, Lee explica cómo los escándalos financieros tras la declaratoria de quiebra de empresas como Enron y WorldCom (con estados financieros certificados por firmas de auditoría multinacionales, supuestamente independientes, las cuales dictaminaron que los respectivos informes reflejaban la realidad económica de esas entidades, en concordancia con los Principios de Contabilidad Generalmente Aceptados -PCGA-) dejaron al descubierto que los altos ejecutivos de estas corporaciones ocultaron, de manera fraudulenta, la verdadera situación económica (substancia) bajo la forma, y en algunos casos convencieron a sus auditores de que los costos de mantenimiento eran realmente costos de capital. En un sistema económico que aprecia proyectos como la contabilidad para la realidad, y virtudes como la fidelidad representacional y la verificabilidad de la información, resulta natural que estos escándalos motivaran una serie de medidas para restablecer la confianza erosionada por normas y enfoques de práctica profesional incapaces de detectar y corregir, oportuna y eficazmente, tales falencias. Los expertos se apresuraron a identificar algunos culpables: la vaguedad y variedad de los PCGA; las múltiples fuentes de donde proceden dichos principios; el elevado número de normas para preparar informes; la actitud pasiva de los contadores, más inclinados a recurrir a normas o principios que privilegian la forma sobre la substancia y a complacer a sus patrones, que a usar sus propios criterios. La expedición del acta Sarbanes-Oxley en 2002, y todas las directrices encaminadas a mejorar las características de los estándares para preparar informes financieros (en términos de menos reglas y excepciones; y mayor calidad, claridad y capacidad de mantener las virtudes asociadas a la fidelidad representacional), y a incrementar el control de los accionistas y los organismos de vigilancia y auditoría sobre las corporaciones, fueron las acciones inmediatas para una solución.

Para el FASB, estas nuevas propuestas mejorarían su MC en relación al reconocimiento y la medición contable, la eliminación de inconsistencias 
conceptuales y la calidad en los informes, además de facilitar la convergencia con otros estándares internacionales por ser compatibles con las normas del IASB y el ASB del Reino Unido'; no obstante, Lee considera que no hubo muchos progresos en la consecución de relevancia, confiabilidad, transparencia, comparabilidad, utilidad para la toma de decisiones y cifras basadas en prácticas de medición y reconocimientoconsistentes, en partedebidoalasuposición-incorrectade que los factores sociales, políticos, económicos y culturales que son relevantes en los Estados Unidos, también lo serían en Australia, Bangladesh o Estonia (The FASB 8). Lee ve muchos objetivos ocultos y diversos compromisos epistemológicos implícitos en el proyecto del FASB (como la presunción de que es posible representar de manera objetiva una realidad económica independiente), y toma la imposición de su perspectiva económica sobre el mundo de los negocios como una forma de imperialismo económico, políticamente motivada y consistente con los principios que guían la investigación contable en Norteamérica (The FASB 10).

Según Lee, el principal problema del proyecto de mejorar la calidad de los informes financieros radica en la renuencia del FASB a abordar y explicar la noción de realidad económica que subyace a su proyecto. Siguiendo a Alexander y Archer (2003) y a Mouck (2004), Lee considera que dicha noción proviene de la teoría de Searle (1995) sobre la realidad social; por lo que dedica la parte restante de su artículo a exponer sus aspectos fundamentales. El autor comienza con las distinciones básicas de la ontología social; a saber, la diferencia entre lo objetivo y lo subjetivo (desde el punto de vista ontológico y epistemológico); los aspectos intrínsecos del mundo y aquellos que son relativos al observador; la distinción entre hechos brutos y hechos sociales; y las nociones de hechos institucionales, reglas regulativas, reglas constitutivas, intencionalidad colectiva, estatus y función. ${ }^{2}$ Tras una exposición breve de dichos conceptos, Lee concluye, siguiendo a Mouck (2004) que la contabilidad se ocupa de "hechos sociales más que de hechos brutos", y ofrece ejemplos de la

\footnotetext{
${ }^{1}$ El FASB y el IASB acordaron, en su reunión de 2004, trabajar en un MC común, y la Comisión Europea y Australia aceptaron usar en sus territorios los estándares contables del IASB. Cabe recordar que mientras el sistema normativo del Reino Unido se orienta al "espíritu de las reglas", en Norteamérica se busca el cumplimiento estricto de "la letra de las reglas", por lo cual resulta lógico que el proyecto mute gradualmente hacia la búsqueda de relevancia y confiabilidad, como cualidades primarias de los informes, y de comparabilidad y consistencia, como cualidades secundarias.

${ }^{2}$ Para una explicación más detallada de estos conceptos y sus antecedentes en el trabajo de Austin(1962) ver el apéndice del capítulo 4 de mi Epistemología de la Contabilidad: Una introducción crítica (2019).
} 
posibilidad de representar la función social en la actividad económica de ciertos objetos, como se puede ver en la definición de "activo" del FASB: "Los activos son los probables beneficios económicos futuros obtenidos o controlados por una entidad particular como resultado de eventos o transacciones pasadas" (The FASB 12).

Pero Lee no está satisfecho con esta definición. Para mejorarla, el FASB debería fortalecer su proyecto a partir de un mejor conocimiento de la ontología y la epistemología subyacentes en su concepción de la contabilidad. Alternativamente, considera que la perspectiva de Macintosh y su equipo no sólo permite incorporar algunos elementos de la ontología social de Searle, sino que es perfectamente compatible con ella; y que, debido a la naturaleza regulativa de las normas contables, los organismos que adoptan los estándares deberían considerar la diferencia entre reglas regulativas y reglas constitutivas. La realidad social, según Lee, también es consistente con el Modelo de la Realidad como Capas de cebolla (MRC) que propone Mattessich, y al mismo tiempo con la hiper-realidad de los modelos autoreferenciales del enfoque de Macintosh; ya que, en última instancia "las prácticas contables financieras están implicadas en la construcción y reproducción del mundo social" (The FASB 15). Dada la inspiración realista de los planteamientos de Searle, el artículo incluye un apartado sobre la teoría correspondentista de la verdad y su eventual utilización en las representaciones contables. Infortunadamente, el tratamiento de Lee a este importante problema está plagado de errores y confusiones. Por ejemplo, confunde reiteradamente la verdad de un enunciado sobre la realidad social con las creencias "de los humanos" sobre el grado de precisión con la que es posible representar un estado de cosas; lo cual le impide examinar problemas como el de la fidelidad representacional desde la perspectiva de una teoría de la verdad objetiva y absoluta. Quizá por ello, Lee acepta, sin cuestionamientos, la afirmación de Mouck (2004) sobre la falta de referente objetivo de una cifra como "renta neta" y pasa por alto la inconsistencia del planteamiento que le atribuye a Macintosh et al. (2000), y a Alexander y Archer (2003) según el cual la utilidad de cifras contables como renta neta, pese a su carácter arbitrario, se debe a su observabilidad, verificabilidad y predictibilidad (The FASB 16).

En resumen, Lee insiste en que el FASB debe explicitar su compromiso con el realismo y la categoría de "realidad social", así como explicar la ontología y la epistemología "inherentes" a sus ECBP. Asumiendo la 
cuestionable tesis de que un organismo regulador no pueda suscribirse implícitamente a una epistemología, aconseja renunciar a la tesis de que los contadores pueden representar (mediante sus teorías) una realidad económica objetiva e independiente, pues no tratan con hechos físicos o brutos, salvo de manera indirecta. Pero tal alejamiento del realismo no se sigue de las tesis de Searle, para quien es dable representar de manera objetiva los hechos sociales que, pese a su carácter especial, constituyen hechos genuinos. ${ }^{3}$ La sugerencia de que la noción de "correspondencia verídica" resultaría mejor servida por la teoría coherentista de la verdad no está bien motivada y revela las dificultades de Lee con el correspondentismo, al igual que la suposición de que el consenso permitirá decidir lo que los contadores pueden hacer cuando se trata de representar la realidad social.

\section{Macintosh: tres posiciones sobre la verdad}

Macintosh reconoce la importancia del debate que Lee inició, comparte las críticas al proyecto de producir ECBP del FASB y añade a los reparos de Lee un cargo de circularidad que afectaría los esfuerzos por fundamentar el MC en las prácticas convencionales (PC) y a su vez buscar que éstas reflejen el MC. También concuerda con la problematización de la tesis de sentido común según la cual los signos contables ("renta" y "capital") reflejan "de una manera fáctica una substancia económica bruta subyacente" (Macintosh, AccountingTruth 23). Pero no está convencido del aporte que pueda hacer la ontología social de Searle a la formulación y solución de los problemas epistemológicos atrás planteados; ya que, en su opinión, el problema de la realidad (al igual que el del realismo) trasciende la distinción entre hechos brutos y hechos sociales. Para exponer su opinión, retoma el conocido ejemplo de Russell "el actual rey de Francia es calvo" y afirma que una vez se pronuncia "el enunciado existe en la forma de un hecho social" (Accounting-Truth 24), pese a que tal existencia no logra hacerlo verdadero o falso "en el sentido de que corresponda a una realidad bruta" (Ibíd.).

Con base en este ejemplo, Macintosh pretende ilustrar que así como en los lenguajes naturales hay diversas expresiones con sentido pero sin denotación; y no experimentamos dificultades para comprenderlas y

\footnotetext{
${ }^{3}$ En este punto, un proyecto que explorara lo que resulta de aplicar las ideas de Searle a la práctica y la teoría contables, sería mucho más útil para la epistemología de la contabilidad.
} 
usarlas en contextos conversacionales o académicos; en el lenguaje de la contabilidad ocurre lo mismo, y conceptos como "renta" o "capital" tienen significado pero carecen de denotación, pues no se refieren a nada real, ni remiten a una supuesta realidad económica subyacente porque, en tanto construcción social, la "realidad económica" no es más que un artificio literario, un relato o un meta-relato mediante el cual se cuentan historias (que se registran en los estados financieros) sobre ciertas propiedades cuantificables que versan sobre derechos $u$ obligaciones o sobre sus cambios a través del tiempo. Así, pese a que actualmente Francia es una república (por lo que no tiene rey) o a que la mayoría de los adultos sabemos que no existe Santa Claus, podemos comprender perfectamente las oraciones mediante las cuales se habla de estas entidades. De hecho, no nos sentimos tentados a suponer que cuando describimos a Santa Claus como un viejo alegre y bonachón, de barba blanca y traje rojo, que trae regalos a los niños en navidad, nos estemos refiriendo a un ser real. Por otra parte, Macintosh acude a la solución russelleana para el problema de la denotación y subraya que, en ciertos contextos, los significantes, pese a estar dotados de sentido, no remiten a nada real ya que su relación con el mundo no es como la describió Wittgenstein en su teoría pictórica del lenguaje, sino que más bien corresponde a enunciados "que se pueden evaluar lógicamente para determinar su verdad o falsedad" (Accounting-Truth 24); y dado que no hay rey en Francia, se sigue que el enunciado en cuestión tiene sentido pero es falso. ${ }^{4}$

Secundando a Baudrillard, Macintosh sostiene que el tratamiento contable tradicional de la renta y el capital va a la par del que reciben las oraciones sobre el actual rey de Francia o Santa Claus: hay significantes dotados de sentido pero carentes de denotación, y en ambos casos podemos usar las nociones involucradas no sólo para referirnos significativamente a entidades de ficción, sino que acudimos a oraciones "descriptivas" que cumplen propósitos y funciones sociales reales, sin importar si tales sujetos existen en el mundo real, o si la realidad económica involucrada existe como una cosa en sí. En apoyo de este

\footnotetext{
${ }^{4}$ Señalo varias dificultades. La primera es que la verdad lógica no es una propiedaddeterminable mediante inspección del mundo o a la realidad. La literatura indica que se opone a la verdad material y depende, exclusivamente, de las propiedades formales de las expresiones por lo que se puede explicar mejor desde la teoría coherentista y no es la clase de noción de verdad que se requiere para esta discusión. La segunda es que se ignoran otras soluciones al problema de Russell, entre ellas la de Strawson (1950) para quien las expresiones que se refieren a individuos y objetos presuponen la existencia (en la realidad) de tales individuos u objetos si las hemos de tratar como proposiciones genuinas.
} 
planteamiento, Macintosh cita la definición que da el FASB de "fidelidad representacional" en términos de correspondencia entre una medida y el fenómeno que se intenta representar; trae a colación la noción de "renta hicksiana", elemento esencial de la representación fidedigna que apoya el concepto de "calidad de las ganancias", junto con la anotación de que aquella no es observable aunque podemos formular buenas aproximaciones a ella mediante la renta comprehensiva y la medición de utilidades, y concluye que los conceptos involucrados en esta discusión han implosionado (en el sentido de Baudrillard) por lo que se pierde definitivamente el vínculo entre el signo y su referencia.

Según Macintosh, los esfuerzos por fundar las reglas o principios contables en un MC firme e inatacable fallan porque no hay una distinción genuina entre reglas y principios. Por eso los intentos de diversos organismos para formular principios fundamentales, atemporales y comprehensivos son deficitarios; y dejan ver que la contabilidad, lejos de ser una ciencia que descansa sobre fundamentos conceptuales sólidos, es una mezcla laberíntica de enunciados axiomáticos, aislados, a menudo inconmensurables y contradictorios, que se exponen como reglas y principios universales para resolver los problemas e implementar las prácticas contables (AccountingTruth 29). Estos reparos al proyecto fundacionalista del FASB encajan perfectamente con las críticas de la filosofía postmoderna a la búsqueda de principios universales y posiciones "totalizadoras", y con su renuncia a la idea de progreso en una trayectoria histórica lineal que conduce a una utopía contable en la cual será posible, finalmente, ofrecer una perspectiva verdadera y justa de la esencia económica de las empresas (Ibíd.). Como otros postmodernos y post-estructuralistas, Macintosh descarta la aplicabilidad de las tesis de Searle a los problemas de la contabilidad, supuestamente porque los límites entre los conceptos básicos de la ontología y los de la epistemología (distinciones básicas en la teoría searleana) son borrosos e indistinguibles.

Macintosh suscribe la tesis que niega la capacidad representacional del lenguaje, la existencia de una realidad económica substancial y objetiva, y que ubica la verdad o falsedad en las oraciones mediante las cuales hablamos del mundo, sin que los referentes estén contenidos en ellas (Nietzsche). Desde esta óptica, la verdad es el resultado de nuestras narrativas sobre el mundo $y$, por tanto, es relativa a las particularidades de nuestras formulaciones lingüísticas. Así, los PCGA devienen micronarrativas independientes de cualquier marco conceptual que, a su 
vez, determinan el significado que se otorga a cada cuenta de un estado financiero. Los métodos para valorar contablemente los inventarios (FIFO, LIFO, o NIFO) también son micro-narrativas sobre la capacidad de generar flujos de caja futuros o su costo histórico, según la preferencia de los contables (Accounting-Truth 31). A esto se añade la actitud (capacidades o poderes agentivos) de los contadores hacia la verdad, al momento de preparar los informes. Según Macintosh, tales actitudes se pueden clasificar en tres categorías representadas, respectivamente, por el contador veraz; el mentiroso y el cañero. El primero se guía por la forma y la substancia de los PCGA y procura responder a las condiciones de los organismos reguladores preparando informes que buscan representar una perspectiva justa y verdadera de la realidad económica de una empresa; y asume una perspectiva realista sobre los fenómenos económicos tratados. El segundo también se interesa por la verdad, pero aleja a los usuarios de la información de lo que ellos creen que es la realidad económica, y distorsiona de manera deliberada los estados financieros para engañar a los jugadores del mercado y obtener beneficios personales. El tercero es indiferente a la verdad del objeto que representa en sus narrativas (Accounting-Truth 33). Puede tomar en cuenta los PCGA, interpretar los principios clave para su informe, apelar al marco conceptual y producir una narración sobre la situación económica de la empresa. También puede llegar a la conclusión de que no existe una realidad económica para representar; que los informes financieros son patrañas o engaños, que no es posible ofrecer una explicación fáctica de "renta" y "capital" sino sólo interpretaciones, y que no existe una verdad contable para descubrir.

\section{Mattessich: una perspectiva realista alternativa}

La respuesta de Mattessich (2009) aporta una perspectiva filosófica importante a la discusión, y reintroduce el tratamiento realista de la realidad económica y social para la epistemología de la contabilidad. El autor considera que su MRC es preferible a las tesis construccionistas de Searle, ya que es más fácil de comprender, está más cerca de la terminología de la contabilidad y del lenguaje ordinario, y permite formular y resolver mejor los problemas que se abordan en esta discusión. El artículo de Mattessich incluye una recapitulación de los planteamientos de Lee y de Macintosh, una exposición de la ontología social de Searle, la comparación de estos planteamientos con su MRC, la presentación de los principales puntos de desacuerdo entre la teoría de Searle y su MRC, una evaluación final sobre el llamado del FASB a 
estructurar un MC que permita fundamentar sus reglas y normas (al tiempo que promueve el desarrollo de ECBP), y un análisis crítico sobre las propuestas de Lee y la postura de Macintosh. Veamos estos temas.

Sobre la insistencia en que el FASB considere "el problema de una realidad construida socialmente y sus representaciones numéricas" (Lee, The FASB 2), y la afirmación de que "la realidad social es subjetiva y que su existencia depende de la observación humana, el consenso y la comunicación" (The FASB 3), Mattessich muestra su carácter contraintuitivo. Si la realidad social es subjetiva, entonces no deberíamos considerar como verificables los derechos de propiedad, las relaciones de acreencia, los costos de adquisición y el valor actual de mercado; y a fortiori, tendríamos que aceptar que las reivindicaciones de propiedad y los derechos de las entidades financieras sobre ciertos inmuebles (garantizados mediante hipoteca) son sólo ilusiones. Pero las consecuencias jurídicas y prácticas de no pagar los préstamos hipotecarios son notorias, y pese a que las dudas de Lee sobre la posibilidad de que el FASB consiga fortalecer el MC, desarrollar ECBP y mejorar sustancialmente la calidad y fidelidad representacional de los informes financieros se justifiquen, Mattessich recomienda separar los problemas prácticos de los teóricos y los meta-teóricos, de suerte que se contribuya a la solución de los primeros, y se progrese en la comprensión de los últimos. Lee le atribuye carácter subjetivo a la realidad social mientras Mattessich critica esta postura. Es extraño llamar "subjetiva" la realidad social. ¿Cómo puede ser, a la vez, real y subjetiva?; ¿no debería mejor considerarse objetiva? (Mattessich 41). Si bien en contabilidad hay contextos en los cuales se emplean ambos adjetivos (los costos de adquisición se consideran objetivos, mientras el valor presente se trata como subjetivo), la principal diferencia reside en el hecho de que el término "objetivo" se usa para calificar proposiciones susceptibles de "verificación", mientras el término "subjetivo" se reserva para calificar el punto de vista personal o a las proposiciones normativas o relativas. Según Mattessich, aplicar los términos "objetivo" y "subjetivo" a los modos de existencia de ciertas entidades (e.g. un objeto físico o un hecho social) genera confusiones. En su teoría, los hechos sociales gozan de un estatus de realidad comparable al de los hechos naturales y la única diferencia es el nivel desde el cual se predica dicha realidad. Así, la gran depresión económica de los años 30 es tan real como la explosión de la supernova de la gran nube de Magallanes en 1987. Pero Lee y otros partidarios de las tesis de Searle evitan "el dilema de las realidades múltiples" distinguiendo entre los 
hechos brutos y los hechos sociales, y calificando como objetivos a los primeros y subjetivos a los segundos (Mattessich 42).

Searle resuelve este problema apelando a la distinción entre los modos de existencia de diversos objetos (ontológicamente objetivo y ontológicamente subjetivo) y a nuestras maneras de conocerlos (epistemológicamente objetiva y epistemológicamente subjetiva). Los hechos institucionales (y los sociales) son ontológicamente subjetivos, ya que su existencia depende del lenguaje, la intencionalidad y, en última instancia, la mente humana; en contraste, los hechos brutos (o naturales) son ontológicamente objetivos. Pero Mattessich discrepa: los términos "objetivo" y "subjetivo" se refieren a proposiciones que corresponden al nivel epistémico, no al ontológico, y de acuerdo con el uso consuetudinario la categoría de "subjetivo" se emplea para designar las experiencias del sujeto mientras la de "objetivo" para referirse a los objetos sobre los cuales versan dichas experiencias (Mattessich 43). ${ }^{5}$ Mattessich pasa a considerar las tesis de Searle sobre la teoría correspondentista de la verdad y su realismo externo. Lamentablemente, no logra apreciar las dificultades de ciertos problemas filosóficos (entre ellos, la imposibilidad de probar doctrinas metafísicas como el realismo) por lo cual descarta el potencial de la postura realista de Searle para la epistemología de la contabilidad, aunque reconoce la importancia de sus herramientas conceptuales para analizar la realidad social.

Mouck, Lee, Alexander y Archer, entre otros, aprovechan las tesis de Searle para vaticinar el ocaso del realismo externo en las discusiones epistemológicas sobre la realidad económica y la contable. Pero, como lo señala Mattessich, dicha predicción es infundada pues Searle está a favor de la representabilidad y el carácter epistémicamente objetivo de los hechos institucionales. Mattessich recurre a su MRC para resolver las dificultades en aquellos puntos donde encuentra insatisfactorio el construccionismo searleano y afirma que las principales diferencias entre la ontología general que se deriva de su MRC y la que se

\footnotetext{
${ }^{5}$ Hay que añadir las enormes diferencias entre ambos en lo que concierne a la concepción de la realidad pues, aunque Searle admite que la realidad social está fundamentada en la física, la biológica y la mental no le concede a los hechos sociales el mismo estatus de realidad que a los hechos físicos. Para Mattessich, los hechos físicos son tan reales en su propio nivel como los sociales en el suyo y, mutatis mutandis, una entidad bancaria -qua institución- es tan real como una piedra.
} 
sigue de la teoría de Searle (clasificables en siete categorías) son terminológicas (Mattessich 50). La primera es que, para él, los términos "objetivo" y "subjetivo" encajan mejor en las discusiones epistémicas, pero son fuente de confusión en el plano de la ontología, y mientras él prefiere un enunciado como "la deuda federal de Norteamérica es una realidad social", Searle diría que "la deuda federal de Norteamérica es ontológicamente subjetiva". La segunda es que la noción searleana de "físico" es muy restrictiva por su fuerte dependencia de los aspectos no-mentales, concretos y tangibles, mientras la suya toma en cuenta los constituyentes básicos de dicho nivel, de donde provienen los fundamentos de "numerosos niveles superiores (y subniveles) de la realidad" (Mattessich 51). Es por eso que, según Mattessich, su MRC puede ofrecer una explicación más detallada y una clasificación más precisa de muchos objetos de la realidad física. La tercera es que él hace más énfasis en las propiedades emergentes para explicar las especificidades de cada nivel de la realidad, y su rol en el paso de un nivel al siguiente, mientras Searle no les concede tanta importancia. La cuarta contrasta el poder del MRC para ofrecer una imagen de la estructura jerárquica de la realidad, con la aparente simplicidad de la ontología de Searle y su dependencia de la distinción entre hechos brutos y hechos sociales. En la quinta, y dado que Searle reconoce la existencia de hasta siete niveles distintos en la ontología, Mattessich insiste en la diferencia de objetivos: mientras el MRC bosqueja la estructura de la realidad como un todo, Searle se concentra en los detalles más finos de la realidad social, que correspondería a uno solo de los niveles en que aquel organiza la realidad, y al hacerlo así mezcla diferentes niveles en una única realidad física a la cual no pertenecen ciertas creaciones humanas, pese a su aspectos físicos. En la categoría seis Mattessich plantea que su teoría favorece mejor una actitud realista hacia la realidad social, pues la tesis searleana sobre el carácter ontológicamente subjetivo de la realidad social puede abrir las puertas a ciertas formas de construccionismo idealista. En la última categoría, Mattessich alega que sus planteamientos incorporan el rol de la evolución en la aparición de los productos socioculturales que constituyen la realidad social, mientras que Searle no dice prácticamente nada al respecto y ni siquiera aclara si los seres humanos pertenecen a la realidad social o a la realidad bruta (Mattessich 53).

En síntesis, el MRC es preferible porque se adapta mejor al uso lingüístico establecido, resulta más simple y evita la confusión, sin mencionar sus muchas coincidencias con la teoría de Searle. Por contraste, el MRC es muy diferente a la teoría de Macintosh 
cuyas inconsistencias son notorias. Por ejemplo, la afirmación realista sobre la existencia de piedras, montañas y átomos que "no son simplemente la creación de las mentes humanas y el lenguaje y que existen como cosas en sí mismas" (Macintosh, The FASB 30), y las sugerencias sobre el carácter epistémico de la verdad, definida mediante la comparación con lo que hay afuera, no son compatibles con el postulado post-estructuralista de que las diferencias entre la ontología y la epistemología implosionan hasta desaparecer. ${ }^{6}$ Mattessich reitera su predilección por el enfoque realista y nos recuerda que la construcción (o reconstrucción) de la realidad en su sentido más amplio requiere la formación de estructuras mentales pero presupone la existencia previa de esa realidad: "los humanos no inventamos la realidad, sino que ella se nos impone a nosotros quienes, a su vez, procuramos conocerla" (Mattessich 55). Mattessich subraya la naturaleza pragmática y metodológica del problema de la valoración pues una cosa es reportar el valor de la acción de Ecopetrol al cierre de las operaciones bursátiles el 31 de enero de 2020, y otra muy distinta ofrecer una valoración exacta de los activos y pasivos de la empresa en esa misma fecha. Para resolver el problema de la "medición" contable de variables como riqueza, ingreso y otras, es preciso distinguir nítidamente entre las nociones y los valores o magnitudes que se les puede atribuir en un momento determinado, ya que una cosa es la propiedad sobre un bien, y otra muy distinta el valor que dicho bien tenga en ese momento. Las eventuales variaciones de esta magnitud no implican que el valor no corresponda a una realidad social (Mattessich 57). Ante tales dificultades, Mattessich acepta usar la terminología de Searle y calificar los costos de adquisición y los precios actuales de mercado como "epistémicamente objetivos", y el valor presente como "epistémicamente subjetivo", siempre y cuando se les reconozca realidad ontológica en el nivel social, ya que recurrimos a todos estos valores para tomar decisiones de compra o inversión, por lo cual representan una realidad social. ${ }^{7}$

\footnotetext{
${ }^{6}$ Para Mattessich este error surge del hecho de que elaboramos conceptos y proposiciones sobre las entidades de las que se ocupa la ontología mediante el lenguaje y al hacerlo recurrimos a la representación conceptual en ontología y epistemología, aunque sus respectivos problemas no se deben confundir ni mezclar, como lo muestra la obra de Bunge quien mantiene ambas subdisciplinas separadas (Mattessich 55).

${ }^{7}$ Mattessich aclara que las constantes modificaciones en la magnitud de una variable contable (como ingreso o renta) no justifican la decisión de excluirla del ámbito de la realidad social, pues ello desconoce su importante rol en la economía y la sociedad.
} 


\section{La respuesta de Lee a Mattessich}

En "The Ontology and Epistemology of Social Reality in Accounting According to Mattessich" (2009), Lee ratifica los argumentos planteados en "The FASB and Accounting for Economic Reality" (2006); se queja de que el FASB no ha atendido sus recomendaciones y de que los organismos que adoptan las normas y los estándares para reportar la información financiera son indiferentes a los problemas de la naturaleza de los hechos contables y de la realidad social. No basta con que el FASB se comprometa con los ideales de relevancia para la toma de decisiones y fidelidad informacional, pues sus esfuerzos por desarrollar ECBP buscan mantener la contabilidad de costos histórica y convencional, incrementando su consistencia y comparabilidad, además de mejorar la imagen y demostrar el profesionalismo de los contadores. Lee cree que, si adoptara la teoría de Searle, el FASB podría incorporar "la ontología y la epistemología asociada con la práctica de la representación contable" (The Ontology 66) y distinguir claramente entre la realidad física, intrínsecamente objetiva, y la realidad social, inherentemente subjetiva y dependiente del pensamiento humano y la comunicación. ${ }^{8}$ Macintosh no aprovecha plenamente la teoría de Searle porque asume que toda realidad es construida socialmente y que no es posible distinguir entre algunos aspectos de la realidad social como "ingreso o capital" y sus representaciones numéricas en términos de "ganancias" o "patrimonio neto", porque ambos conceptos devienen hiper-realidades desde las cuales la ontología determina la epistemología ( $y$ viceversa).

En la sección central, Lee evalúa el MRC mediante la exposición de la teoría de los distintos niveles de la realidad y de las propiedades emergentes que explican el carácter único y distintivo de cada nivel respecto a los precedentes. También explica el argumento de Mattessich a favor de la naturaleza real y objetiva de los fenómenos de cada nivel, lo cual apoya la existencia fáctica y objetiva de la realidad social. Lee resume en seis puntos las principales diferencias entre el MRC y la

\footnotetext{
${ }_{8}^{8}$ Pero Lee no capta bien la distinción epistemológicamente objetivo/subjetivo, que no radica en la "relativa verdad de los enunciados que construimos sobre la realidad social" (The Ontology 66) sino en los mecanismos que empleamos para determinar o establecer su valor de verdad. Los enunciados epistemológicamente objetivos son aquellos cuyo valor de verdad se determina mediante la inspección del estado de cosas que se realiza en el mundo (la acción de ISA cerró a \$28000 en la última jornada bursátil), mientras que el valor de verdad de los enunciados epistemológicamente subjetivos depende de nuestras actitudes mentales hacia ellos (creo que la acción de Avianca ya alcanzó su cotización mínima).
} 
teoría de Searle, así como su propio juicio sobre las propuestas del primero. La definición de "objetivo" del MRC otorga a la realidad "el estatus de un objeto visible o tangible" (The Ontology 69) mientras que Searle define "objetivo" como "aquello que es independiente de la conciencia de la mente humana" (Ibíd.). Lee considera que, además de la confusión que introduce, esta diferencia no permite comparar las tesis de Mattessich y las de Searle. En el punto dos, Lee admite los importantes avances de Mattessich sobre una contabilidad para la realidad social y apoya el argumento de que quienes adoptan estándares contables incorporen estas discusiones en su actividad. Curiosamente, fustiga la estructura crítica del artículo de Mattessich (exposición de las debilidades en la argumentación rival y presentación de los puntos fuertes propios) pues esto conduce a "una torre de babel académica"; adicionalmente, reclama una prueba empírica de la eventual mayor facilidad de los contadores para entender y aplicar el MRC. En el punto tres, Lee reitera que quienes adoptan estándares contables han dejado de lado diversas contribuciones teóricas (incluyendo las de Mattessich y Searle) en su afán por integrar objetivos de información $\mathrm{y}$ conceptos que provienen de visiones encaminadas a demostrar el profesionalismo de los contadores, en lugar de examinar la capacidad de dichas teorías para proporcionar estándares que puedan producir cifras confiables y representar una realidad social relevante para la contabilidad. Lee encuentra la teoría de Searle más relevante para la contabilidad debido a que su objeto principal es la realidad social "desprovista de realidad física" (The Ontology 70) y fundamenta este planteamiento en la opinión de Macintosh sobre el carácter tautológico de muchas representaciones numéricas de la contabilidad que tratan la realidad social como "ontológica y epistemológicamente subjetiva" y la suposición de que, en contabilidad, la ontología y la epistemología se confunden. ${ }^{9}$ En el quinto punto, Lee analiza la motivación de Mattessich para rechazar la idea de que la ontología de la realidad social dependa de las mentes humanas y preferir su versión realista en la cual se hereda y reconstruye dicha realidad en un proceso evolucionista. Lee menciona los investigadores contables que encuentran convincentes los planteamientos deSearle y, sobre todo, que admiten el carácter subjetivo de la ontología involucrada en la contabilidad, aunque va más lejos y concluye que, en el caso de conceptos como "ganancia" y "capital", la ontología y la epistemología de la realidad social se entremezclan. Por

\footnotetext{
${ }^{9}$ Como se ha reiterado, esta conclusión no podría estar más lejos de las tesis de Searle, en cuya teoría pretende basarse Lee.
} 
último, afirma que si los encargados de adoptar estándares aceptaran los argumentos de Mattessich a favor de la objetividad de la ontología de la realidad social, entonces correríamos el riesgo de que el "proceso de reconstrucción intergeneracional tendría lugar únicamente en el mundo de la contabilidad" (The Ontology 70) por lo que el modelo actual que trata nociones como "ganancia" y "capital" apoyado en el costo histórico y la subjetividad podría desaparecer.

\section{Conclusiones}

Como vimos, Lee reitera su predilección por el enfoque construccionista de la realidad social para la reevaluación periódica de la ontología y la epistemología de dicha realidad e insiste en que el FASB ha hecho poco para incorporarlo en las revisiones de su MC; ignora el "significado ontológico y la función de la realidad social tal como ganancias y capital y las representaciones epistemológicas como utilidades o patrimonio bruto" (The Ontology 71); no comprende el papel de la realidad social en la contabilidad, a juzgar por las acciones desplegadas con ocasión de las crisis financieras globales, y tampoco capta los problemas del significado implícitos en los cambios en la ontología de la realidad social que llevan al tratamiento de activos y obligaciones financieras como cuentas de largo plazo en vez de corto plazo. Estas críticas, sumadas a la queja por el carácter ingenuo de las presuposiciones del FASB sobre la naturaleza de la realidad económica, las condiciones de los informes financieros que aspiran a entregar una representación fidedigna de dicha realidad, y la eventual capacidad de la contabilidad para reflejar adecuadamente los hechos económicos y las transacciones comerciales pertinentes reflejan un prejuicio infundado sobre el carácter heurístico y el potencial epistemológico del sentido común y el desconocimiento de que hay un firme hilo conductor que lo une con el realismo mejor articulado que podamos encontrar. Quizá el FASB adopte y recomiende mejores estándares para estructurar los informes financieros si está familiarizado con los pormenores de la ontología social de Searle; pero no se prueba esta hipótesis porque el realismo ingenuo (atribuido al FASB) se base en razonamientos del sentido común. Además, apelar a intuiciones desde la actitud natural o la filosofía del sentido común (como sería el caso del realismo del FASB) no basta para desacreditar las conclusiones sobre la importancia de reflejar la substancia económica de las transacciones comerciales en los informes financieros. Lee no dice nada, filosóficamente relevante, sobre los escándalos financieros ocurridos en los últimos años y extrañamente achaca la manipulación 
deliberada y malintencionada de la información contable, y las consecuentes quiebras de empresas a una perspectiva epistemológica en particular, si bien es cierto que ciertos enfoques (sobre todo aquellos que rechazan el carácter representacional de la contabilidad) dificultan la identificación oportuna de la verdadera situación económica de una organización. Por esto, los llamados del FASB a incrementar el uso del criterio profesional, minimizar las excepciones, evitar el riesgo de que los altos ejecutivos manipulen los resultados financieros, y disminuir el rol de la interpretación en el proceso de reporte, parecen un paso en la dirección correcta de la representación justa o fiel de la situación económica de cualquier empresa (compatible con el sentido común y con el enfoque realista).

No son muy pertinentes las acusaciones (sin argumentos y evidentemente ideologizadas) de "imperialismo económico" contra cualquier enfoque que favorezca la producción de representaciones contables objetivas de la realidad económica, como tampoco las críticas al hecho de que organismos como el FASB y el IASB se suscriban (conscientemente o no) a la tesis de que hay un mundo real con hechos "objetivos y subjetivos" que se pueden observar y representar de manera objetiva o subjetiva. La epistemología no consiste en "el método de estudiar la realidad" (The FASB 11) y evaluar la epistemología de la realidad social no proporciona "metodologías adecuadas de representación" (The Ontology 70), como afirma Lee; cuya exposición de la teoría de Searle confunde conceptos de la contabilidad -una disciplina social- (como "beneficios económicos futuros", "el acto de obtener", "el acto de controlar") con hechos sociales, y clasifica como "hechos sociales" entidades que no corresponden a esta categoría, como los conceptos de "evidencia", "lógica" e "incertidumbre comercial". La combinación de las tesis realistas de Searle con el enfoque baudrillardiano de Macintosh et al. y la mención del MRC de Mattessich, sin una discusión adecuada de sus similitudes y diferencias con respecto a las propuestas del primero, resulta bizarra y revela una perspectiva ecléctica.

Pese a la cuidadosa revisión que ofrece Macintosh del artículo de Lee, es evidente que malinterpreta el alcance de algunos de sus variados planteamientos filosóficos. No es claro que Lee rechace de plano la perspectiva realista sobre la relación entre los signos contables y sus referentes, ni que solucione este problema acogiendo las tesis de Searle y tratando la noción de realidad económica como 
una entidad construida socialmente (Accounting-Truth 23). Por otra parte, la explicación de Macintosh del famoso ejemplo de Russell "el actual rey de Francia es calvo" es errónea: no es cierto que una vez pronunciada esta oración exista como un hecho social, porque entonces todas las emisiones lingüísticas darían lugar a hechos sociales, lo cual incrementaría arbitraria e innecesariamente los objetos que constituyen dicha ontología. La definición searleana de "hechos sociales" atiende a características bien diferentes: un hecho social es un tipo de fenómeno creado mediante la función performativa del lenguaje, requiere intencionalidad colectiva, reconocimiento, consenso y aceptación; pero, sobre todo, existe de manera objetiva gracias a la concurrencia de esos elementos. Por ejemplo, el performativo "declaro aprobados los estados financieros" genera un hecho social; a saber, la sanción o aprobación legal o reglamentaria de un documento público por el cuerpo competente (consejo, asamblea). Sus efectos sociales no dependen del mero hecho de que se haya pronunciado la fórmula de rigor, pues se necesitan ciertas condiciones adicionales que terminan por ser ignoradas en las afirmaciones de Macintosh sobre la supuesta existencia (como entidad lógica) de un enunciado alguna vez pronunciado.

Macintosh no capta correctamente el problema de las expresiones que tienen sentido pero no denotación, ya que compara "El actual rey de Francia es calvo" con las nociones contables de "renta" y "capital". Es evidente que la primera locución tiene sentido pero no denota nada en la actualidad porque en Francia ya no hay Rey, mientras que los conceptos de "renta" y "capital" denotan aspectos concretos de la realidad económica de las empresas que, si bien existen gracias a la ontología social y a los poderes deónticos del lenguaje, no por ello son menos reales que los objetos físicos, como ya vimos. Es claro que las oraciones en las que se usan estos términos no se parecen en nada al enunciado de Russell, pues tienen sentido y denotación (a menos que se acepte la tesis post-estructuralista de que tales nociones han perdido contacto con la realidad). Es dudoso que la existencia de Santa Claus (y los enunciados que expresan tal existencia, distinción que Macintosh deja de lado) no se deba estudiar con herramientas analíticas formales, que nos tengamos que contentar con considerar este caso simplemente como un "enunciado lógico socialmente construido" (AccountingTruth 25) y que debamos concentrarnos en sus funciones sociales pues, aunque Macintosh cita a Searle para apoyar esta interpretación, es obvio que los planteamientos del filósofo norteamericano van por un 
camino muy distinto, como se infiere de su firme compromiso con el realismo. ${ }^{10}$ Algo similar puede decirse de las críticas a los conceptos de "ganancias verdaderas", "desempeño económico subyacente", y "más representacionalmente fiel al ingreso hicksiano" pues se basan en el hecho de que las ganancias reales y la riqueza económica verdadera subyacente no son definibles ni observables, lo cual no implica "que existen como cosas en sí mismas, independientemente de las mentes humanas, antes de que sean capturadas en los informes contables" (Accounting-Truth 26). El argumento falla pues hay numerosas entidades inobservables en el mundo natural que también son difíciles de definir, pero sobre cuya realidad y precedencia ontológica respecto a los enunciados que hablan de ellas no abrigamos dudas. Al examinar las características de las teorías científicas, no clasificamos las partículas sub-atómicas junto con las entidades de ficción y otras creaciones lógico-lingüísticas carentes de denotación. Lo apropiado en este contexto es resolver las dificultades para definir esas nociones contables y tratarlas como a las múltiples entidades inobservables de las ciencias naturales."

Las observaciones de Macintosh sobre la verdad o falsedad de las oraciones del lenguaje mediante las cuales nos referimos al mundo apuntan en la dirección correcta al afirmar que la verdad "reside" en ellas. ${ }^{12}$ Sus conclusiones sobre el carácter relativista de la verdad y la inconveniencia de una actitud realista hacia los fenómenos económicos son discutibles. El problema surge por no reconocer y distinguir apropiadamente el rol de los portadores de verdad y el de los hacedores de verdad (según la teoría correspondentista). La verdad se predica de entidades lingüísticas, como lo capta Macintosh, pero se determina en el mundo (natural o social) al que se refieran dichas entidades. Son los fenómenos del mundo (y su correspondencia o falta de correspondencia con los enunciados) los que hacen verdaderas o falsas las proposiciones. Por esto mismo no queda claro lo que tiene en mente Macintosh cuando dice que los contadores mentirosos también se interesan en la verdad y

\footnotetext{
${ }^{10}$ Cfr. Searle (1995) capítulos 7 y 8, pp.149-197.

${ }^{11}$ Esta sugerencia despierta el rechazo inmediato de los partidarios de separar tajantemente las ciencias naturales de las sociales en razón a la gran diferencia entre sus respectivos objetos. Sin embargo, como lo sugiere Mattessich, se trata de reconocer estatus de realidad a los objetos designados por los conceptos de la teoría contable (en su nivel) del mismo modo que otorgamos estatus de realidad a los objetos designados por las teorías físicas.

12 Según la teoría correspondentista de la verdad, ésta radica en la concordancia entre el contenido objetivo de las proposiciones y el mundo. Por lo tanto, si bien la verdad se predica de las entidades lingüísticas (y así podría pensarse que "reside" en las oraciones del lenguaje) el papel del mundo es fundamental para poder determinarla.
} 
que los cañeros son indiferentes al respecto, a menos que esto signifique un interés por tergiversar la verdad lo cual suena a falsedad deliberada. Por otra parte, su posición sobre las actitudes de los distintos contadores hacia la verdad y la naturaleza ontológica de los fenómenos económicos y contables es inestable, como se deduce de algunos fragmentos en los que parece conceder existencia independiente a los hechos económicocontables, mientras que en otras partes lo niega, y de su insistencia en que las discusiones teóricas en contabilidad deberían enfocarse mejor en el problema de qué tipo de informes se están realizando, de cuán objetivamente representan la realidad de la que se ocupa esta disciplina, así como en los retos y dificultades que crean los contadores cañeros para el mundo económico y las decisiones que se toman en la sociedad.

Mattessich subraya la poca compatibilidad del complejo vocabulario filosófico de la teoría de Searle y las nociones y conceptos propios de la contabilidad, y está en lo correcto al reclamar insistentemente el estatus de realidad para las entidades de las cuales se ocupa dicha disciplina. En este punto, Searle (2010) podría ser un aliado importante pues admite la realidad de los conceptos contables y recomienda una inspiración realista para la epistemología de la contabilidad. Como lo documenta y reconoce ampliamente Mattessich (Mattessich 48), no hay por qué comparar el construccionismo realista de Searle, con el constructivismo idealista (o subjetivista) que defienden algunos postmodernos, por lo cual resulta infundada su preocupación por reivindicar las explicaciones de la teoría evolucionista, cuya capacidad para describir los hechos de la biología no cuestiona Searle. ${ }^{13}$ Son muy atinadas las críticas de Mattessich a Macintosh por aplicar las tesis de Baudrillard a ciertos problemas contables como el de la valoración, pues no es que las crisis del mercado de valores ilustren la "irrealidad" o "hiper-realidad" de la vida moderna, sino que el valor de las acciones o los bonos de deuda fluctúa y puede incluso desaparecer; lo que no compromete su estatus de realidad, al igual que la desintegración de una partícula subatómica no significa que ésta no sea real ni que el proceso mismo no corresponda a una realidad física; y aunque es posible explicar los problemas de la valoración atribuyéndolos a los estándares contables, resulta más razonable tomar en cuenta para ello los defectos de un sistema monetario y financiero basado en realidades sociales como el "sobre-apalancamiento", la creación indefinida de

\footnotetext{
${ }^{13}$ Searle (The construction 16 y ss.) está familiarizado con la teoría de Darwin. Por otra parte, el título de su libro menciona el carácter real de los hechos, instituciones, y estructuras sociales construidas mediante los actos del habla.
} 
crédito sin respaldo adecuado, la ambición y el fraude, característicos en las prácticas económicas actuales (Mattessich 56).

Como acabamos de ver, los principales argumentos epistemológicos de este debate pasan por la disputa entre el realismo y el anti-realismo; la elección de un enfoque construccionista útil para la teoría y la epistemología de la contabilidad; la escogencia entre una concepción representacional de las teorías y conceptos de la contabilidad o las contrapartidas que niegan la existencia de una realidad económica subyacente y sostienen que los conceptos de la contabilidad carecen de referente. Pese a que las posiciones de Lee y Macintosh son algo inestables, queda claro que el primero suscribe el construccionismo social de Searle pero tiene algunos coqueteos con las posiciones postmodernas, mientas el segundo resulta un claro partidario de las tesis anti-realistas de Baudrillard. En este mar de confusiones sobresale el realismo de Mattessich, cuyo enfoque epistemológico (a pesar de algunos vacíos y dificultades) resulta la mejor alternativa para una epistemología de la contabilidad que conserve el realismo y se preocupe por virtudes como la fidelidad representacional de los informes financieros.

\section{REFERENCIAS}

Alexander, David \& Archer, Simon. "On economic reality, representational faithfulness and the 'true and fair override'". Accounting and Business Research, vol. 33, no. 1, 2003, pp. 3-17. https:/ / doi.org/10.1080/00014788.2003.9729628

Austin, John L. How to do things with words. Glasgow: Oxford University Press, 1962.

Berger, Peter L. y Luckman, Thomas (1968). La construcción de la realidad social. Buenos Aires: Amorrortu.

García D., Carlos E. Epistemología de la Contabilidad. Una introducción crítica. Manizales: Universidad de Manizales, 2019.

Lee, Thomas A. A systematic view of the history of the world of accounting. Accounting, Business \& Financial History. 1 (2), 1990: 73-107.

Lee, Thomas A."The FASB and Accounting for Economic Reality". 
Accounting and the Public Interest, vol. 6, 2006, pp. 1-21.

Lee, Thomas A.. "The Ontology and Epistemology of Social Reality in Accounting According to Mattessich". Accounting and the Public Interest, vol. 9, 2009, pp. 65-72.

Macintosh, Norman B., Shearer, Teri, Thornton, Daniel B., Welker, Michael. "Accounting as simulacrum and hyper-reality: perspectives on income and capital". Accounting, Organizations and Society, vol. 25, 2000, pp. 13-50. https://doi.org/10.1016/S0361-3682(99)00010-0

Macintosh, Norman B.. Accounting and the Truth of Earnings Reports: Philosophical Considerations. European Accounting Review. Vol. 18, 2009, no. 1, pp. 141-175.

Macintosh, Norman B. "Accounting-Truth, Lies or 'Bullshit'? A Philosophical Investigation". Accounting and the Public Interest, vol. 6, 2006. pp. 22-37. https://dx.doi.org/10.2139/ssrn.1006875

Mattessich, Richard. "FASB and Social Reality - An Alternate Realist View". Accounting and the Public Interest, vol. 9, 2009, pp. 39-63.

Mouck, Tom. "Institutional reality, financial reporting and the rules of the game". Accounting, Organizations and Society, vol. 29, 2004, pp. 525-541. https://doi.org/10.1016/S0361-3682(03)00035-7

Russell, Bertrand. “On denoting”. Mind Vol. 14, No. 56, 1905, pp. 479-493.

Searle, John. The Construction of Social Reality. Free Press, 1995.

Searle, John. Making the social world. The structure of Human Civilization. Oxford University Press, 2010.

Strawson, Peter F. “On referring”. Mind, vol. 59, no. 235, 1950, pp. 320-344. 